\title{
Cautionary High-resolution Computed Tomography Findings for the Presence of Facial Canal Dehiscence in Patients with Cholesteatoma
}

\author{
Deniz Baklac1 ${ }^{1}$, İhsan Kuzucu ${ }^{2}$, İsmail Guler ${ }^{3}$, Rauf Oğuzhan Kum ${ }^{4}$, Müge Özcan ${ }^{4}$ \\ 1. Otolaryngology, Kahramankazan State Hospital, Ankara, TUR 2. Otolaryngology, Aksaray University Faculty of \\ Medicine, Aksaray, TUR 3. Otolaryngology, Medipol University School of Medicine, Ankara, TUR 4. Otolaryngology, \\ Ministry of Health Ankara City Hospital, Ankara, TUR
}

Corresponding author: Deniz Baklac1, doktorent@gmail.com

\section{Abstract \\ Objective}

This study aimed to investigate the abnormal high-resolution computed tomography (HRCT) findings in cholesteatomatous chronic otitis media (CCOM) patients preoperatively and the coexistence of abnormal HRCT findings with facial canal dehiscence (FCD) observed intraoperatively to identify the predictive factors associated with FCD.

\section{Methods}

The medical records of 151 CCOM patients who had undergone tympanomastoidectomy at our center were retrospectively examined in terms of the patients' age and gender, preoperative HRCT findings [scutum defect, posterior wall of external auditory canal (PWEAC) defect, lateral semicircular canal (LSSC) defect, tegmen defect, and sigmoid plate erosion]. Operation records containing information about FCD were also analyzed.

\section{Results}

The prevalence of FCD was found to be $33.8 \%$ (51/151). There was a significant correlation between the presence of scutum, PWEAC, LSSC, and tegmen defects and the presence of FCD. However, no statistically significant correlation was found between the presence of sigmoid plate erosion and the presence of FCD. The results of regression analysis of the coexisting pathologic findings for FCD showed that the risk of FCD was highest in patients with LSSC + scutum defects (34.3-fold increase), followed by LSSC + PWEAC defects (31.6-fold increase).

\section{Conclusion}

Received 01/13/2020 Review began 01/17/2020 Review ended 01/18/2020 Published 01/21/2020

๑ Copyright 2020 Baklacı et al. This is an open access article distributed under the terms of the Creative Commons Attribution License CC-BY 3.0., which permits unrestricted use, distribution, and reproduction in any medium, provided the original author and source are credited.
Our study revealed that the presence of scutum, PWEAC, LSSC, and tegmen defects on HRCT indicates a higher risk of FCD preoperatively. This risk is even greater when multiple abnormal findings coexist.

Categories: Otolaryngology, Radiology, Anatomy

Keywords: facial canal dehiscence, cholesteatoma, chronic otitis media, computed tomography, predictive factor

\section{Introduction}

Facial paralysis is one of the most feared complications encountered during cholesteatoma surgery. The rate of iatrogenic facial paralysis was reported as $15 \%$ in the mid-20th century [1]. With the development of high-magnification microscopes and motorized drills, this rate has been drastically reduced. Recently, the reported risk of facial injury is $0.6-3.6 \%$ for primary surgery and $4-10 \%$ for revision surgery [2].

The risk of injury during surgery is high in cases of dehiscence of the facial nerve (FN) canal [3,4]. Facial canal dehiscence (FCD) may be caused by developmental defects due to failure during the ossification process of the bony canal or bony erosion resulting from cholesteatoma and inflammation. The most common location is at the tympanic segment, with a majority of these dehiscences occurring through the inferior and underside of the FN adjacent to the oval window at the rates of $73.5 \%$ and $55 \%$, respectively $[5,6]$. In the literature, the rate of FCD varies from 1 to $74 \%$ [5-9]. Li et al. have reported the rate of FCD as $11.4 \%$ in stapedectomies [10]. The incidence of FCD was also found to be high in patients with chronic otitis media (COM), ranging from 18 to 34\% [3,11]. FCD was reported to occur at a higher rate during revision surgery than primary surgery [12]. Therefore, the status of the facial canal during COM surgery remains a challenging issue even for experienced surgeons. Intraoperatively, some pathological conditions such as scutum erosion, defects of the posterior wall of the external auditory canal (PWEAC), labyrinth fistula, complete ossicular chain defect, and the presence of cholesteatoma were found to be important signs for the prediction of FCD [13-15]. 
Iatrogenic FN damage may occur during the removal of cholesteatoma from the middle ear cavity, epitympanum, and mastoid cavity. Thus, it is essential to accurately evaluate the facial canal anatomy and its relationship with the surrounding pathology in these cases. Obtaining a clear picture of the ear anatomy based on detailed radiographic information concerning the bony canal of FN and determining the extension and site of cholesteatoma can minimize the likelihood of FN damage during surgery. Furthermore, FCD has been considered to be a negative prognostic factor for surgical outcome in COM surgery [16]. In this regard, high-resolution computed tomography (HRCT) of the temporal bone provides valuable data since it can determine the cholesteatoma tissue and its extent, and assess the ossicles, facial canal, tegmen, PWEAC, bony plate over the sigmoid sinus and jugular vein, carotid canal, and inner ear structures [17-19]. Low-lying dura or anteriorly located sigmoid sinuses, which are considered important in mastoid surgery, can also be visualized preoperatively via HRCT scanning. When the surgeon has good knowledge of temporal bone anatomy and its relationship with the adjacent structures mentioned above, s/he can decide on the type of surgery (i.e., open or closed technique) and inform the patient about possible complications. However, the sensitivity of HRCT is low in the detection of preoperative FCD; thus, some authors have suggested that routine preoperative HRCT examination prior to uncomplicated COM surgery was of questionable value $[14,17,20,21]$. Therefore, in addition to having good knowledge of anatomy, the surgeon must also consider the conditions in which the FCD rates may be high.

In the present study, we aimed to investigate the abnormal HRCT findings in cholesteatomatous COM (CCOM) patients preoperatively and the coexistence of abnormal HRCT findings with FCD observed intraoperatively. We strove to identify the predictive factors associated with FCD based on preoperative HRCT findings and facilitate preemptive prediction of FCD.

\section{Materials And Methods}

The medical records of 151 CCOM patients who had undergone tympanomastoidectomy at our center between 2014 and 2019 were reviewed. The data collected retrospectively included the patients' age and gender, preoperative HRCT findings (scutum defect, PWEAC defect, lateral semicircular canal (LSSC) defect, tegmen defect, and sigmoid plate erosion. We also obtained operation records containing information about FCD. The exclusion criteria were having a history of COM surgery or temporal bone trauma, congenital cholesteatoma, middle ear pathologies except for COM, lack of preoperative HRCT scans, and presence of congenital inner ear anomalies.

Facial canal observations were performed by experienced surgeons using an operating microscope and confirmed by palpation with a blunt pick. Intraoperative FN monitoring was used only in complicated cases. The patients were categorized into two groups based on intraoperative observation of the facial canal: Group 1 with FCD and Group 2 without FCD. The groups were compared in terms of preoperative abnormal HRCT findings mentioned above.

The local ethics committee approved the research (2019/06-21). The study was performed in compliance with the Declaration of Helsinki. Written informed consent was obtained from all participants prior to surgery.

HRCT was performed using scanners with 64-detector rows (Toshiba Aquilion TSX-101A; Canon Medical Systems Corporation, Otawara, Japan) using the following scan parameters - detector collimation: $0.5 \mathrm{~mm}$; tube voltage: $120 \mathrm{kV}$; tube current: $250 \mathrm{~mA}$; and rotation time: 1.0 seconds.

\section{Statistical analysis}

Statistical Package for the Social Sciences (SPSS) software v. 20 (IBM Corporation, Armonk, NY) was used for statistical analyses. The data were expressed as mean and standard deviation (SD). The chi-square test was employed for the comparison of the groups. The Shapiro-Wilk test was used to check the normality of the data. The Student's t-test was utilized for parametric variables. A logistic regression analysis was undertaken to investigate the predictive role of preoperative HRCT findings associated with FCD in univariate analyses. P-values of less than 0.05 were considered statistically significant.

\section{Results}

A total of 151 patients with 151 operated ears (80 left, 71 right) who met the aforementioned criteria were evaluated. The demographic and clinical features of the patients are given in Table 1 . There were no statistically significant differences between the two groups in terms of age (p:0.393) and gender (p: 0.670). 


\section{Cureus}

\begin{tabular}{|c|c|c|}
\hline & Number (total: 151) & Percentage \\
\hline Age, years (mean $\pm S D$ ) & $42.08 \pm 15.41$ & \\
\hline \multicolumn{3}{|l|}{ Gender } \\
\hline Female & 66 & 43.7 \\
\hline Male & 85 & 56.3 \\
\hline \multicolumn{3}{|l|}{ Side operated } \\
\hline Left & 80 & 52.9 \\
\hline Right & 71 & 47.1 \\
\hline \multicolumn{3}{|l|}{ FCD } \\
\hline Absent & 100 & 66.2 \\
\hline Present & 51 & 33.8 \\
\hline \multicolumn{3}{|l|}{ Scutum defect } \\
\hline Absent & 40 & 26.5 \\
\hline Present & 111 & 73.5 \\
\hline \multicolumn{3}{|l|}{ PWEAC defect } \\
\hline Absent. & 45 & 29.8 \\
\hline Present & 106 & 70.2 \\
\hline \multicolumn{3}{|l|}{ LSSC defect } \\
\hline Absent & 126 & 83.4 \\
\hline Present & 25 & 16.6 \\
\hline \multicolumn{3}{|l|}{ Tegmen defect } \\
\hline Absent & 136 & 90.1 \\
\hline Present & 15 & 9.9 \\
\hline \multicolumn{3}{|l|}{ Sigmoid plate erosion } \\
\hline Absent & 134 & 88.7 \\
\hline Present & 17 & 11.3 \\
\hline
\end{tabular}

\section{TABLE 1: Demographic and clinical characteristics of the study group}

FCD: facial canal dehiscence; PWEAC: posterior wall of external auditory canal; LSSC: lateral semicircular canal; SD: standard deviation

There were 111 patients with scutum defects, and 48 of these patients (43.2\%) had FCD. FCD without a scutum defect was determined in three of 40 patients (7.5\%). The correlation between scutum defect and FCD was statistically significant [p: $<0.001$; odds ratio (OR): 9.39; 95\% confidence interval (CI): 2.73-32.31] (Table 2). 


\section{Cureus}

\begin{tabular}{|c|c|c|c|c|c|}
\hline Clinical characteristics & FCD & WITHOUT FCD & OR & $95 \% \mathrm{Cl}$ & P-value \\
\hline \multicolumn{6}{|l|}{ Scutum defect, n (\%) } \\
\hline Absent & $3(7.5)$ & 37 (92.5) & \multirow{2}{*}{9.4} & \multirow{2}{*}{$2.73-32.31$} & \multirow{2}{*}{$<0.001$} \\
\hline Present & 48 (43.2) & $63(56.8)$ & & & \\
\hline \multicolumn{6}{|l|}{ PWEAC defect, n (\%) } \\
\hline Absent & $8(17.8)$ & 37 (82.2) & \multirow{2}{*}{3.1} & \multirow{2}{*}{$1.34-7.44$} & \multirow{2}{*}{0.009} \\
\hline Present & $43(40.6)$ & $63(59.4)$ & & & \\
\hline \multicolumn{6}{|l|}{ LSSC defect, n (\%) } \\
\hline Absent & $30(23.8)$ & 96 (76.2) & \multirow{2}{*}{16.8} & $5.34-52.80$ & $<0.001$ \\
\hline Present & $21(84)$ & $4(16)$ & & & \\
\hline \multicolumn{6}{|l|}{ Tegmen defect, n (\%) } \\
\hline Absent & 42 (30.9) & 94 (69.1) & \multirow{2}{*}{3.3} & \multirow{2}{*}{$1.12-10.04$} & \multirow{2}{*}{0.024} \\
\hline Present & $9(60)$ & $6(40)$ & & & \\
\hline \multicolumn{6}{|c|}{ Sigmoid plate erosion, $\mathrm{n}(\%)$} \\
\hline Absent & 42 (30.9) & $92(69.1)$ & \multirow{2}{*}{2.4} & \multirow{2}{*}{$0.89-6.83$} & \multirow{2}{*}{0.076} \\
\hline Present & $9(52.9) \quad \longrightarrow$ & $8(47.1)$ & & & \\
\hline
\end{tabular}

\section{TABLE 2: Comparison of the groups in terms of abnormal HRCT findings}

HRCT: high-resolution computed tomography; FCD: facial canal dehiscence; PWEAC: posterior wall of external auditory canal; LSSC: lateral semicircular canal, SD: standard deviation; OR: odds ratio; Cl: confidence interval

A total of 106 patients had PWEAC defect, of whom 43 (40.6.\%) had FCD. FCD without PWEAC defect was determined in eight of 45 patients (17.8\%). The correlation between PWEAC defect and FCD was statistically significant (p: 0.007; OR: 3.16; 95\% CI: 1.34-7.44).

LSSC defects were detected in 25 patients, of whom 21 (84.0\%) had FCD. Thirty of 126 patients (23.8\%) were found to have FCD without an LSSC defect. A statistically significant correlation was detected between LSSC defect and FCD (p: <0.001; OR: 16.80; 95\% CI: 5.34-52.80).

There were 15 patients with tegmen defects, with nine of them (60.0\%) having FCD. FCD without a tegmen defect was observed in 42 of 136 patients (30.9\%). The correlation between tegmen defect and FCD was statistically significant (p: 0.024; OR: 3.36; 95\% CI: 1.12-10.04).

Of the 17 patients with sigmoid plate erosion, nine (52.9\%) had FCD. Forty-two of 134 patients (31.3\%) had FCD without sigmoid plate erosion. There was no statistically significant correlation between sigmoid plate erosion and FCD (p: 0.076; OR: 2.46; 95\% CI: 0.89-6.83). The results of the regression analysis for FCD in patients with coexisting HRCT abnormalities are given in Table 3.

\begin{tabular}{|c|c|c|c|c|}
\hline & Number (\%) & OR & $95 \% \mathrm{Cl}$ & P-value \\
\hline Scutum + LSSC & $23(15.2)$ & 34.3 & $7.60-154.79$ & $<0.001$ \\
\hline PWEAC + LSSC & 22 (14.6) & 31.6 & $6.99-142.90$ & $<0.001$ \\
\hline
\end{tabular}

TABLE 3: Results of regression analysis for FCD in patients with coexisting HRCT abnormalities

HRCT: high-resolution computed tomography; FCD: facial canal dehiscence; PWEAC: posterior wall of external auditory canal; LSSC: lateral semicircular canal; OR: odds ratio; Cl: confidence interval 


\section{Cureus}

\section{Discussion}

Today, HRCT has become the most important and standard imaging modality in COM patients due to the detailed information it provides prior to surgical interventions on bony structures, including possible variations and complications. HRCT shows the localization and spread of pathological soft tissues in COM patients. It also allows visualization of the pathology of areas that cannot be examined otoscopically, such as the posterior tympanic area and facial recess.

Previous studies have demonstrated a good correlation between HRCT scans and surgical findings, particularly in scutum, ossicular chain and sigmoid plate erosion, and PWEAC and LSSC defects. However, there are concerns that HRCT lacks guaranteed sensitivity and specificity for the determination of FCD. In the literature, the sensitivity rates of HRCT for the FCD range from 0 to $100 \%$ while the reported specificity rates for FCD are considerably higher [19-27]. Tatlipinar et al. determined that the thin bone covering the FN was occasionally difficult to evaluate owing to partial volume averaging with adjacent soft tissue; thus, the authors were able to detect 35 of 39 (89.7\%) FCD using HRCT with a negative predictive value of 89.7\% [17]. Similarly, HRCT was reported to be unsuccessful in the determination of FCD by some authors. For example, O'Reilly et al. identified only four out of nine FCD cases, and Freng et al. one in four cases [28,29]. In contrast, O'Donoghue et al. successfully detected all nine of the FCD cases they investigated; however, they had six false positives [30].

Due to the relative low sensitivity of HRCT in detecting FCD compared to other anatomical temporal bone structures, some authors suggest using intraoperative findings to predict FCD with higher accuracy. In this regard, Ozbek et al. found that the presence of an LSSC defect or tegmen erosion of $>1 \mathrm{~cm}$ significantly increases the risk of FCD. The risks for FCD were 22.5 and 12.06 times higher in patients with LSSC and tegmen defects, respectively [13]. Similarly, Gulustan et al. reported that the likelihood of FCD was significantly higher in patients with an LSSC defect (24.2-fold increase), PWEAC defect (4.1-fold increase), or a stapes defect [15]. In an HRCT study investigating the radiological and surgical correlation in patients with FCD and coexisting abnormalities, the authors reported that LSSC defect was highly associated with FCD [19]. Our results are consistent with previous studies since we also calculated the risk of FCD to be 16.8, 3.1 and 3.3 times higher in patients with LSSC (Figure 1), PWEAC, and tegmen defects, respectively. Additionally, when LSSC and PWEAC defects coexisted in a patient, the risk of FCD was 31.6 times higher.

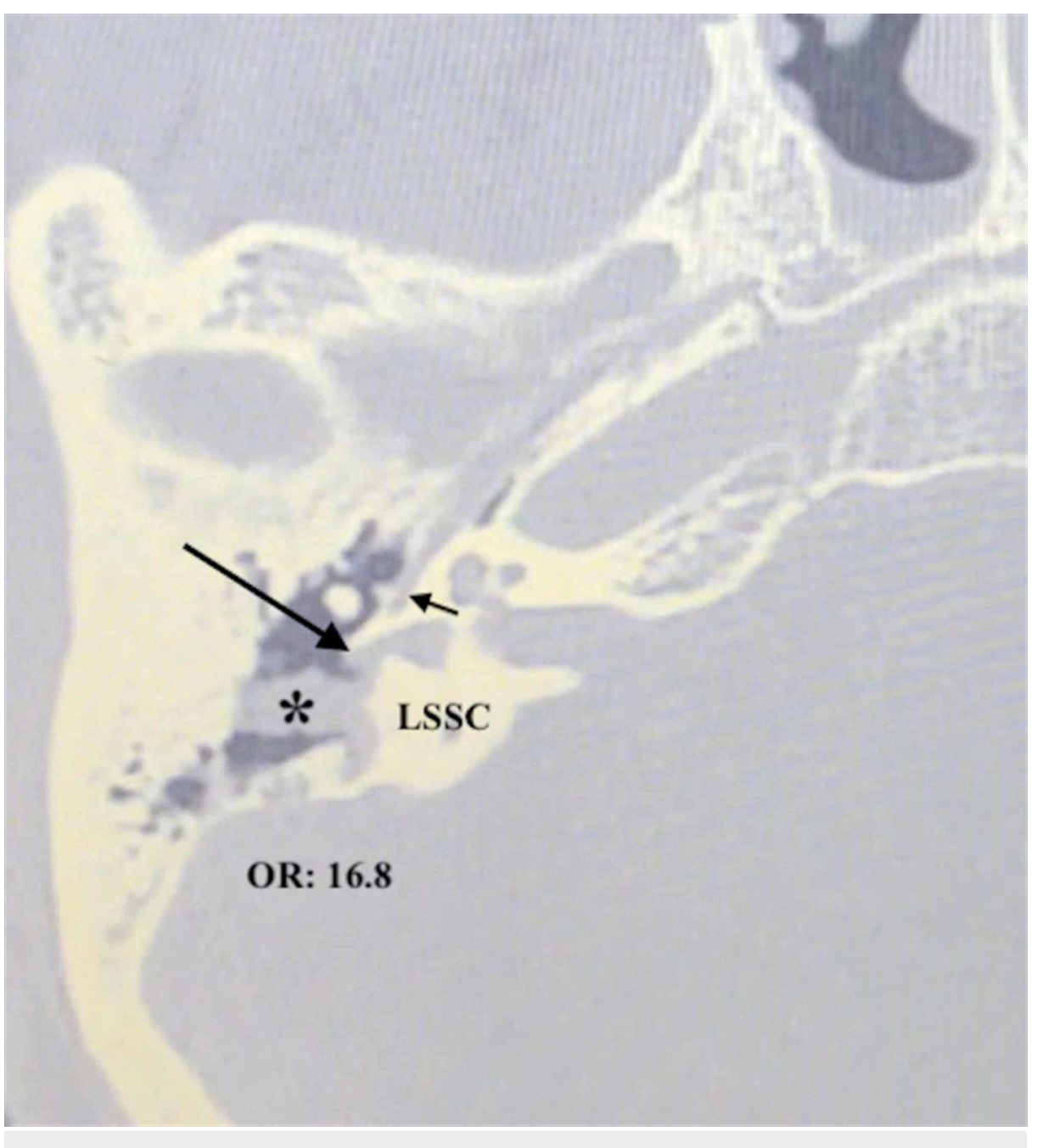




\section{Cureus}

\section{FIGURE 1: LSSC defect caused by cholesteatoma}

LSSC: lateral semicircular canal; OR: odds ratio

*cholesteatoma

Long arrow: labyrinth fistula caused by cholesteatoma; short arrow: facial canal dehiscence

Genc et al. observed FCD in 55.5\% of patients with scutum defects [14]. In the present study, $43.2 \%$ of patients with scutum defects had FCD, indicating a 9.4 times higher risk compared to patients without a scutum defect (Figure 2). Therefore, preoperative indications about LSSC, PWEAC, and scutum defects should be considered as a warning sign for the presence of FCD.

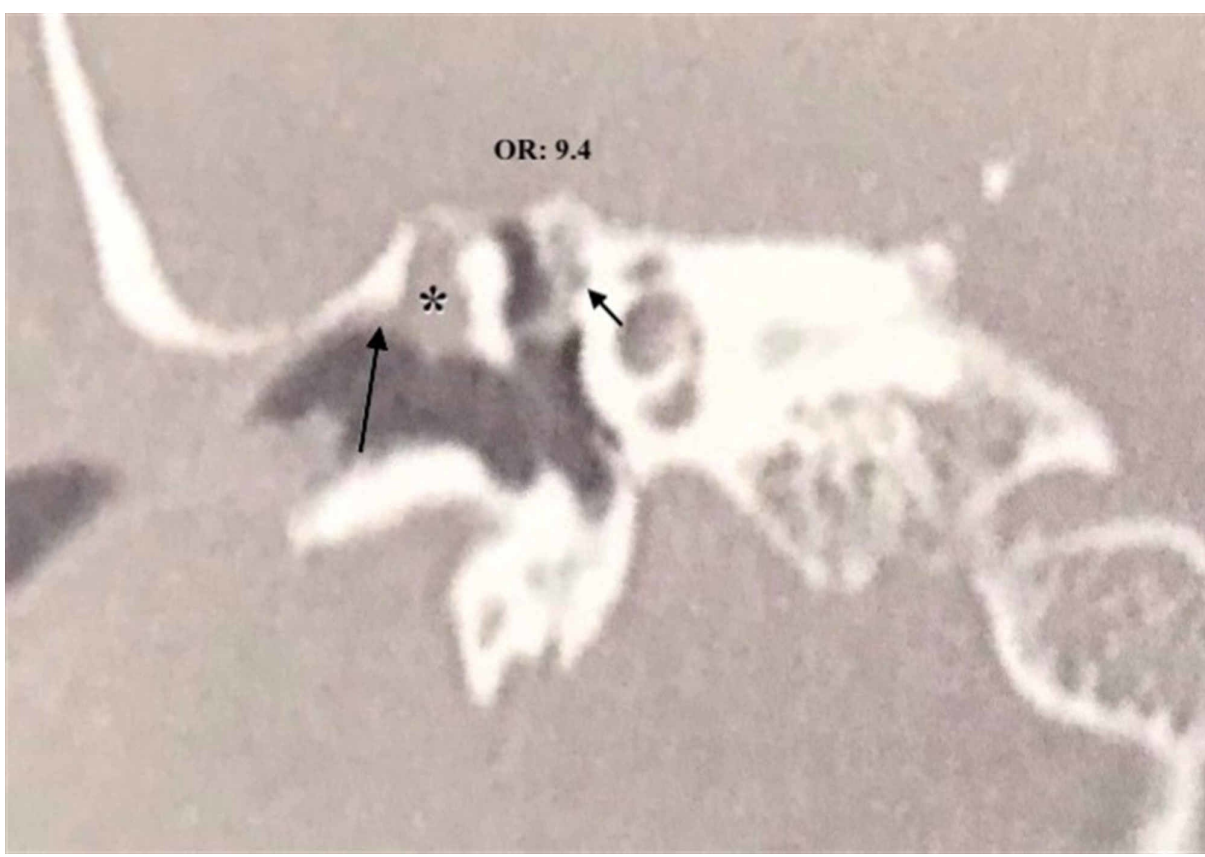

\section{FIGURE 2: Scutum defect caused by cholesteatoma}

OR: odds ratio

*cholesteatoma

Long arrow: scutum defect; short arrow: facial canal dehiscence

In some CCOM patients, especially those with an extended disease, abnormal HRCT findings may coexist. In this study, the results of regression analysis of the coexisting pathologic findings for FCD showed that the risk of FCD was highest in patients with LSSC + scutum defects (34.3- fold increase), and LSSC + PWEAC defects (31.6- fold increase). It can be stated that as the cholesteatoma extends in the middle ear, the likelihood of FCD increases.

There are two limitations to be addressed in this study. Firstly, some personal biases may have crept in during the evaluation of HRCT scans or surgical findings. Secondly, in retrospective studies, some of the records obtained from medical charts may be incomplete or lost in the course of time, leading to missing data. Further prospective studies can provide more reliable and accurate data that could provide stronger evidence for the role and importance of HRCT in determining FCD.

\section{Conclusions}

Our study revealed that the presence of scutum, PWEAC, LSSC, and tegmen defects on HRCT indicates a higher risk of FCD preoperatively. This risk is even greater when multiple abnormal findings coexist. Given that the imaging of the facial canal is much more difficult than imaging these structures, we believe that our findings are important for otologic surgery. 


\section{Additional Information \\ Disclosures}

Human subjects: All authors have confirmed that this study did not involve human participants or tissue. Animal subjects: All authors have confirmed that this study did not involve animal subjects or tissue. Conflicts of interest: In compliance with the ICMJE uniform disclosure form, all authors declare the following: Payment/services info: All authors have declared that no financial support was received from any organization for the submitted work. Financial relationships: All authors have declared that they have no financial relationships at present or within the previous three years with any organizations that might have an interest in the submitted work. Other relationships: All authors have declared that there are no other relationships or activities that could appear to have influenced the submitted work.

\section{References}

1. Shambaugh GE, Glasscock ME: Facial nerve decompression and repair. Surgery of the ear. Gulya JA, Minor BL, Poe DE (ed): W.B. Saunders Company, Philadelphia, PA; 1959. 1:546.

2. Wiet RJ: Iatrogenic facial paralysis. Otolaryngol Clin North Am. 1982, 15:773-780.

3. Selesnick SH, Lynn-Macrae AG: The incidence of facial nerve dehiscence at surgery for cholesteatoma . Otol Neurotol. 2001, 22:129-132. 10.1097/00129492-200103000-00002

4. Green JD Jr, Shelton C, Brackmann DE: Iatrogenic facial nerve injury during otologic surgery. Laryngoscope. 1994, 104:922-926. 10.1288/00005537-199408000-00002

5. Moreano EH, Paparella MM, Zelterman D, Goycoolea MV: Prevalence of facial canal dehiscence and of persistent stapedial artery in the human middle ear: a report of 1000 temporal bones. Laryngoscope. 1994, 104:309-320. 10.1288/00005537-199403000-00012

6. Baxter A: Dehiscence of the Fallopian canal. An anatomical study . J Laryngol Otol. 1971, 85:587-594. 10.1017/s0022215100073849

7. Nilssen EL, Wormald PJ: Facial nerve palsy in mastoid surgery. J Laryngol Otol. 1997, 111:113-116. $10.1017 /$ s0022215100136618

8. Ballester M, Blaser B, Häusler R: Stapedotomy and anatomical variations of the facial nerve. (Article in French). Rev Laryngol Otol Rhinol (Bord). 2000, 121:181-186.

9. Tange RA, de Bruijn AJ: Dehiscences of the horizontal segment of the facial canal in otosclerosis . ORL J Otorhinolaryngol Relat Spec. 1997, 59:277-279. 10.1159/000276953

10. Li D, Cao Y: Facial canal dehiscence: a report of 1,465 stapes operations . Ann Otol Rhinol Laryngol. 1996, 105:467-471. 10.1177/000348949610500609

11. Moody MW, Lambert PR: Incidence of dehiscence of the facial nerve in 416 cases of cholesteatoma . Otol Neurotol. 2007, 28:400-404. 10.1097/01.mao.0000247824.90774.22

12. Ozbek C, Somuk T, Ciftci O, Ozdem C: Management of facial nerve paralysis in noncholesteatomatous chronic otitis media. B-ENT. 2009, 5:73-77.

13. Ozbek C, Tuna E, Ciftci O, Yazkan O, Ozdem C: Incidence of fallopian canal dehiscence at surgery for chronic otitis media. Eur Arch Otorhinolaryngol. 2009, 266:357-362. 10.1007/s00405-008-0748-z

14. Genc S, Genc MG, Arslan IB, Selcuk A: Coexistence of scutum defect and facial canal dehiscence . Eur Arch Otorhinolaryngol. 2014, 271:701-705. 10.1007/s00405-013-2479-Z

15. Gülüstan F, Aslan H, Songu M, Başoğlu MS, Katılmış H: Relationships between facial canal dehiscence and other intraoperative findings in chronic otitis media with cholesteatoma. Am J Otolaryngol. 2014, 35:791795. 10.1016/j.amjoto.2014.04.002

16. Ocak E, Beton S, Mulazimoglu S, Meco C: Does dehiscence of the facial nerve canal affect tympanoplasty results?. J Craniofac Surg. 2016, 27:e374-376. 10.1097/SCS.0000000000002635

17. Tatlipinar A, Tuncel A, Öğredik EA, Gökçeer T, Uslu C: The role of computed tomography scanning in chronic otitis media. Eur Arch Otorhinolaryngol. 2012, 269:33-38. 10.1007/s00405-011-1577-z

18. Jaswal A, Jana AK, Sikder B, Sadhukhan SK, Jana U, Nandi TK: Fallopian canal dehiscence: can it be pridicted. Indian J Otolaryngol Head Neck Surg. 2008, 60:11-15. 10.1007/s12070-008-0006-0

19. Gunbey HP: Facial canal dehiscence and coexisting abnormalities; radiological-surgical correlation. J Clin Anal Med. 2017, 8:121-124. 10.4328/JCAM.4966

20. Mardassi A, Nabil M, Safa K, et al.: Limits of conventional temporal bone computed tomography in the management of cholesteatoma otitis media: report of 96 cases. Egyptian J Otolaryngol. 2014, 30:73-77. 10.4103/1012-5574.133174

21. Gerami H, Naghavi E, Wahabi-Moghadam M, Forghanparast K, Akbar MH: Comparison of preoperative computerized tomography scan imaging of temporal bone with the intra-operative findings in patients undergoing mastoidectomy. Saudi Med J. 2009, 30:104-108.

22. Sadoghi M, Yazdani N, Sharifian H, Saidi M, Izadparasti Y: The validity of computed tomography in complicated chronic otitis media. Iran J Radiol. 2007, 4:175-179.

23. Badran K, Ansari S, Al Sam R, Al Husami Y, Iyer A: Interpreting pre-operative mastoid computed tomography images: comparison between operating surgeon, radiologist and operative findings. J Laryngol Otol. 2016, 130:32-37. 10.1017/S0022215115002753

24. Yildirim-Baylan M, Ozmen CA, Gun R, Yorgancilar E, Akkuş Z, Topcu I: An evaluation of preoperative computed tomography on patients with chronic otitis media. Indian J Otolaryngol Head Neck Surg. 2012, 64:67-70. 10.1007/s12070-011-0271-1

25. Gomaa MA, Abdel Karim AR, Abdel Ghany HS, Elhiny AA, Sadek AA: Evaluation of temporal bone cholesteatoma and the correlation between high resolution computed tomography and surgical finding. Clin Med Insights Ear Nose Throat. 2013, 6:21-28. Accessed: January 21, 2020: https://www.ncbi.nlm.nih.gov/pubmed/24179410. 10.4137/CMENT.S10681

26. Prata AAS, Antunes ML, de Abreu CEC, Frazatto R, Lima BT: Comparative study between radiological and surgical findings of chronic otitis media. Int Arch Otorhinolaryngol. 2011, 15:72-78. 


\section{Cureus}

27. Rogha M, Hashemi SM, Mokhtarinejad F, Eshaghian A, Dadgostar A: Comparison of preoperative temporal bone ct with intraoperative findings in patients with cholesteatoma. Iran J Otorhinolaryngol. 2014, 26:7-12. 10.22038/IJORL.2014.2020

28. O'Reilly BJ, Chevretton EB, Wylie I, et al.: The value of CT scanning in chronic suppurative otitis media . J Laryngol Otol. 1991, 105:990-994. 10.1017/s0022215100118031

29. Freng A, Larsen PL, Nordshus T: Cholesteatomas of the temporal bone. Preoperative CT versus peroperative findings. Scand Audiol. 1988, 30:185-188.

30. O'Donoghue GM, Bates GJ, Anslow P, Rothera MP: The predictive value of high resolution computerized tomography in chronic suppurative ear disease. Clin Otolaryngol Allied Sci. 1987, 12:89-96. 10.1111/j.13652273.1987.tb00168.x 